\title{
Geomagnetic Storm Related to Disturbance Storm Time Indices
}

\author{
Jyh-Woei Lin
}

\section{ABSTRACT}

The magnitude of the Disturbance Storm Time (Dst) index varied in relation to the extremely small negative integer that indicated a large geomagnetic storm. The large sharpened variants of negative Dst indices could describe the detailed features of a geomagnetic storm. the Dst index was estimated using an algorithm through time and frequency-domain band-stop filtering to remove the solar-quiet variation and the mutual coupling effects between the Earth's rotation, the Moon's orbit, and the Earth's orbit around the Sun. A good geomagnetic model that could describe the true variations in the geomagnetic field when undergoing diverse space weather, and one that could even predict variations in the geomagnetic field with a high accuracy. A suitable temporal resolution for the Dst index was per hour.

Keywords: Disturbance Storm Time (Dst) index, Geomagnetic Storm, SolarQuiet Variation, Earth's Rotation, Moon's Orbit, Earth's Orbit.
Published Online: November 05, 2021

ISSN: $2684-446 \mathrm{X}$

DOI : $10.24018 /$ ejgeo.2021.2.6.199

\section{Jyh-Woei Lin*}

Binjiang College, Nanjing University of Information Science \& Technology, Wuxi, 214105, Jiangsu Province, China.

Department of Electrical Engineering, Southern Taiwan University of Science and Technology, Tainan, Taiwan.

(e-mail: email: pgjw11966@gmail.com)

*Corresponding Author

\section{INTRODUCTION}

The Disturbance Storm Time (Dst) index was a physical quantity unit of NanoTesla (nT). One NanoTesla was equal to $10^{-9}$ Tesla, and one Tesla was equal to one weber per square meter $\left(\mathrm{Wb} / \mathrm{m}^{2}\right)$. The magnitude of the Dst index varied in relation to the extremely small negative integer that indicated a large geomagnetic storm shown in Fig.1. Thus, the large sharpened variants of negative Dst indices could describe the detailed features of a geomagnetic storm [1]-[4]. They also indicated when the solar wind has pushed the boundary of the magnetosphere and the conditions of the magnetopause and magnetic tail, inside the geosynchronous orbit [5][13]. Simultaneously, they could also clearly record the arrival times of geomagnetic storms [14]-[16]. The Dst index was estimated from the measurements obtained at stations based on the International Real-time Magnetic Observatory Network (INTERMAGNET) [17].

\section{DISCUSSION}

Since 1975, the Geostationary Operational Environmental Satellite system (GOES system) has been used to monitor space weather. The GOES magnetometers of GOES system were used to monitor the Earth's magnetosphere during geomagnetic storms [5], [19]. The GOES system was built by the United States National Oceanic and Atmospheric Administration (NOAA). It could support weather forecasting, severe storm tracking, and meteorology research connected with ground-based receiver stations, such as ground-based magnetometer stations, and could provide a continuous stream of environmental data, including the parameters of space weather, e.g., the Dst index. The Dst index was derived from hourly scalings of the horizontal magnetic variation, which indicated the effect of the globally symmetric westward-flowing high-altitude equatorial ring current [2], [20], so the ring current depressed worldwide in the horizontal component of Earth's magnetic field with hourly H-component magnetic variations, especially during large magnetic storms. After that, the Dst index was estimated using an algorithm through time and frequency-domain bandstop filtering to remove the solar-quiet variation and the mutual coupling effects between the Earth's rotation, the Moon's orbit, and the Earth's orbit around the Sun [21], [22]. In order to build a good geomagnetic model that could describe the true variations in the geomagnetic field when undergoing diverse space weather, and one that could even predict variations in the geomagnetic field with a high accuracy. Then, a suitable temporal resolution for the Dst index was per hour. However, the geomagnetic model must be able to describe a more accurate characterization of the local auroral absorption rather than the general global state with higher temporal resolution, as it was an important area (auroral area) of research [23], [24].

\section{CONCLUSIONS}

The magnitude of the Dst index varied in relation to the extremely small negative integer that indicated a large geomagnetic storm. The large sharpened variants of negative Dst indices could describe the detailed features of a geomagnetic storm. The Dst index was estimated from the measurements obtained at stations based on the INTERMAGNET. The Dst index was derived from hourly 
scalings of the horizontal magnetic variation, which indicates the effect of the globally symmetric westward-flowing highaltitude equatorial ring current, so the ring current depressed worldwide in the horizontal component of Earth's magnetic field with hourly H-component magnetic variations, especially during large magnetic storms. a good geomagnetic model that could describe the true variations in the geomagnetic field when undergoing diverse space weather, and one that could even predict variations in the geomagnetic field with a high accuracy. Then, a suitable temporal resolution for the Dst index may be per hour.

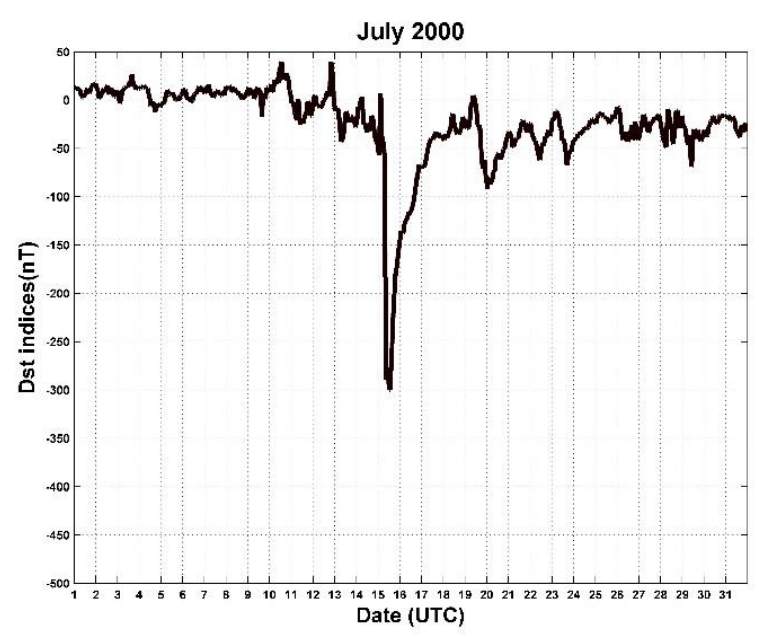

Fig. 1. Plot of the Dst indices (unit nT) for July 2000 (UTC) The horizontal time scale from 1 to 2 indicates the variation in the Dst indices on 01 July 2000 as an example. The later figures with horizontal time scales are consistent with this scale on the horizontal axis, including those in the main text. The geomagnetic storm that occurred during this month during solar cycle 23 was named the Bastille Day event [18].

\section{DATA AVAILABILITY}

World Data Centre for Geomagnetism, Kyoto.

Source of the Dst indices: http://wdc.kugi.kyotou.ac.jp/dst_final/index.html.

\section{ACKNOWLEDGMENTS}

The author is grateful to the World Data Center for Geomagnetism, Kyoto, M. Nose, T. Iyemori, M. Sugiura, T. Kamei (2015), Geomagnetic Dst index, doi:10.17593/1451574000 .

The author is also grateful the supporting of Prof. Dr Yuan Mei in Taiwan and all of my friends in Taiwan and China

\section{CONFLICTS OF INTEREST}

The author declares that there is no conflict of interest.

\section{AUTHOR CONTRIBUTIONS}

designed the research; performed the research; analyzed the data; and wrote the paper.

\section{REFERENCES}

[1] H. S. Jones, "Geomagnetism," 1st Edition, Annals of the International Geophysical Year, Vol. 4, ELSEVIER, 197 pp, 1957. ISBN: 9781483226477

[2] W. H. Campbell, "Geomagnetic storms, the Dst ring-current myth and lognormal distributions," Journal of Atmospheric and Terrestrial Physics, Vol. 58 (10), pp. 1171-1187, 1996. doi: 10.1016/00219169(95)00103-4.

[3] K. Mursula, L. Holappa, A. Karinen, "Correct normalization of the Dst index," Astrophysics and Space Sciences Transactions, Vol. 4 (2), pp. 41-45, 2008. doi: 10.5194/astra-4-41-2008.

[4] M. Jawad, A. Rafique, I. Khosa, I. Ghous, J. Akhtar, S. M. Ali, "Improving Disturbance Storm Time Index Prediction Using Linear and Nonlinear Parametric Models: A Comprehensive Analysis," IEEE Transactions on Plasma Science, Vol. 47 (2), pp. 1429-1444, 2019. doi: 10.1109/TPS.2018.2887202.

[5] H. Singer, L. Matheson, R. Grubb, A. Newman, D. Bouwer, "Monitoring space weather with the GOES magnetometers, Proceedings, Vol. 2812, GOES-8 and Beyond," 1996 Internal Symposium on Optical Science, Engineering, and Instrumentation, SPIE (the international society for optics and photonics), 1996. doi: 10.1117/12.254077.

[6] J. E. Borovsky, M. H. Denton, "Magnetic field at geosynchronous orbit during high-speed stream-driven storms: Connections to the solar wind, the plasma sheet, and the outer electron radiation belt," Journal of Geophysical Research: Space Physics, Vol. 115, A8, 2010. doi: doi.org/10.1029/2009JA015116.

[7] D. C. Ferguson, S. P. Worden, D. E. Hastings, "The Space Weather Threat to Situational Awareness, Communications, and Positioning Systems," IEEE Transactions on Plasma Science, Vol. 43 (9), pp. 3083098, 2015. doi: 10.1109/TPS.2015.2412775.

[8] N. Lugaz, C. J. Farrugia, C. L. Huang, R. M. Winslow, H. Spence, N. A. Schwadron, "Earth's magnetosphere and outer radiation belt under sub-Alfvénic solar wind," Nature Communications, Vol. 7, 13001 2016. doi: 10.1038/ncomms13001.

[9] J. P. Fulbright, E. Kline, D. R. Pogorzala, W. MacKenzie, J. Sims, R. Garnett, C. Burnett, M. Seybold, "Calibration/validation status for GOES-16 L1b data products," Proceedings, Earth Observing Systems XXII; 104020T, SPIE (the international society for optics and photonics), Vol. 10402, 2017. doi: 10.1117/12.2274358.

[10] V. V. Kalegaev, N. A. Vlasova, I. S. Nazarkov, S. A. Melkova, "Magnetospheric access for solar protons during the January 2005 SEP event," Journal of Space Weather and Space Climate, Vol. 8, A55, 2018. doi:10.1051/swsc/2018040.

[11] T. M. Loto'aniu, R. J. Redmon, S. Califf, H. J. Singer, W. Rowland, S. Macintyre, C. Chastain, R. Dence, R. Bailey, E. Shoemaker, F. J. Rich, D. Chu, D. Early, J. Kronenwetter, M. Todirita, "The GOES-16 Spacecraft Science Magnetometer," Space Science Reviews, Vol. 215, 32, 2019. doi: 10.1007/s11214-019-0600-3.

[12] S. Califf, D. Early, M. Grotenhuis, T. M. Loto'aniu, J. Kronenwetter, "Correcting the Arcjet Thruster Disturbance in GOES-16 Magnetometer Data," Vol. 18 (1), 2020. e2019SW002347, doi: 10.1029/2019SW002347.

[13] J. McCorkel, B. Efremova, J. Hair, M. Andrade, B. Holben, "GOES16 ABI solar reflective channel validation for earth science application," Remote Sensing of Environment, Vol. 237, 111438, 2020. doi: 10.1016/j.rse.2019.111438.

[14] R. J. Redmon, D. B. Seaton, R. Steenburgh, J. He, J. V. Rodriguez, September 2017's Geoeffective Space Weather and Impacts to Caribbean Radio Communications During Hurricane Response, Vol. 16 (9), pp. 1190-1201, 2018. doi: 10.1029/2018SW001897.

[15] A. Gil, R. Modzelewska, S. Moskwa, A. Siluszyk, M. Siluszyk, A. Wawrzynczak, M. Pozoga, L. Tomasik, "The Solar Event of 14-15 July 2012 and Its Geoeffectiveness," Solar Physics, Vol. 295, 135, 2020. doi: 10.1007/s11207-020-01703-2.

[16] Piersanti, M., Michelis, P., D., Moro, D. D., Tozzi, R., Pezzopane, M., Consolini, G., Marcucci, M. F., Laurenza, M., Matteo, S. D., Pignalberi, A., Quattrociocchi, V. and Diego, P., 2020, From the Sun to Earth: effects of the 25 August 2018 geomagnetic storm, Annales Geophysicae, Vol. 38 (3), 703-724, doi: 10.5194/angeo-38-703-2020.

[17] J. W. Lin, "Real-time Magnetic Observatory Network: A Review," European Journal of Environment and Earth Sciences, Vol. 2(5), pp. 1-2, 2021. doi: 10.24018/ejgeo.2021.2.5.177.

[18] S. Watari, M. Kunitake, Watanabe, "The Bastille Day (14 July 2000) event in Historical Large Sun-Earth Connection Events," Solar Physics, Vol. 204, pp. 425-438, 2001.

[19] J. J. Love, "Magnetic monitoring of earth and space," Physics Today, Vol. 61 (2), pp. 31-37, 2008. doi: 10.1063/1.2883907. 
[20] T. L. Pulkkinen, N. Y. Ganushkina, E. L. Tanskane, M. Kubyshkina, G. D. Reeves, M. F. Thomsen, C. T. Russell, H. J. Singer, J. A. Slavin, J. Gjertoev, "Magnetospheric current systems during stormtime sawtooth events," Journal of Geophysical Research: Space Physics, Vol. 111, 2006. A11S17, doi: 10.1029/2006JA011627.

[21] J. J. Love, J. L. Gannon, "Revised Dst and the epicycles of magnetic disturbance: 1958-2007," Annales Geophysicae, Vol. 27 (8), pp. 31013131, 2009. Doi: 10.5194/angeo-27-3101-2009.

[22] J. L. Gannon, J. J. Love, "USGS 1-min Dst index," Journal of Atmospheric and Solar-Terrestrial Physics, Vol. 73, no. 2-3, pp. 323334, 2011. doi: 10.1016/j.jastp.2010.02.013.

[23] M. Mandea, M. Korte, "Geomagnetic Observations and Models, Springer, Netherlands, 344 pp, 2011. ISBN: 978-90-481-9857-3, doi: 10.1007/978-90-481-9858-0.

[24] L.A. Dremukhina, L. G. Lodkina, Y. I. Yermolaey, Relationship between the Parameters of Various Solar Wind Types and Geomagnetic Activity Indices," Cosmic Research, Vol. 56, pp, 426433, 2018. doi: 10.1134/S0010952518060011.

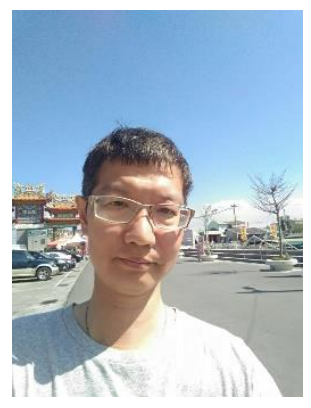

Jyh-Woei Lin received the B.Sc. degree from the Department of Physics, Chung Yuan Christian University, Chung Li City, Taiwan, in 1989, the M.Sc. degree from the Institute of Geophysics, National Central University, Chung Li City, in 1991, the Ph.D. degree from the Institut für Geophysik, ClausthalZellerfeld, Technische Universit ät Clausthal, Germany, in 2000, and the Ph.D. degree from the Department of Electrical Engineering, Southern Taiwan University of Science and Technology, Tainan, Taiwan, in 2019. Since 2019, he is a researcher in the Department of Electrical Engineering, Southern Taiwan University of Science and Technology. Until 2021, he has 71 SCI (SCIE) and EI papers include artificial intelligence, space physics, geophysics, medical sciences, and remote sensing; especially four books publications in Germany and two books in USA. After September 2020, he is also as a Professor in Binjiang College, Nanjing University of Information Science \& Technology, Wuxi, Jiangsu Province, China. 